\title{
A RANDOMIZED COMPARATIVE STUDY BETWEEN REMOTE ISCHEMIC PRECONDITIONING AND PHARMACOLOGICAL PRECONDITIONING IN MAJOR AORTIC SURGERIES
}

\author{
Gihan S. El Nasr, Dalia A. Nasr, Neveine G. Fahmy, John N. Naseef and \\ Mohamed R. Salama
}

Department of Anesthesia \& Intensive
Care and Pain Management
Faculty of Medicine - Ain Shams
University
Corresponding:
Mohamed R. Salama
Mobile 01002987138
Email:
dr_ragheb100@hotmail.com
Received: 26/2/2020
Accepted: 28/3/2020

Online ISSN: 2735-3540

\begin{abstract}
Background: Cardiopulmonary bypass (CPB) remains an essential element of the surgical correction of most major cardiovascular lesions. CPB is complicated by multisystem injury, the mechanisms of which include ischemia-reperfusion injury (IRI) and a detrimental systemic inflammatory response. Cardiac, pulmonary and neuronal injury and dysfunction remain important clinical problems after $C P B$.
\end{abstract}

Aim of the study: The aim of this study was to compare and evaluate the effectiveness of remote ischemic preconditioning and pharmacological preconditioning in reducing cardiac injury induced by cardiopulmonary bypass in adult patients undergoing major aortic surgeries.

Patients and Methods: This study included (42) patients, divided into two groups 21 patients each, Group R: Remote Ischemic Preconditioning (cycles of ischemia and reperfusion of lower limb using blood pressure cuff) and Group P: pharmacological preconditioning (administration of sevoflurane and dexmedetomidine).

Results: The current studyshowed postoperative lower elevation in $C K$ total enzyme, CK MB enzyme and troponin I enzyme and decreased inotropic support(adrenaline infusion) requirements postoperatively along with shorter duration of postoperative intubation and postoperative ICU stay in group Pcompared to group $R$.

Conclusion: Pharmacological preconditioning using sevoflurane and dexmedetomidine hasmyocardial protective effect after $C P B$ in adult patients undergoing major aortic surgeries more than remote ischemic preconditioning as reflected by lower elevation in $C K$ total enzyme, CK MB enzyme and troponin I enzyme and decreased inotropic support (adrenaline infusion) requirements postoperatively along with shorter duration of both postoperative intubation and postoperative ICU stay.

Keywords: cardiopulmonary bypass, ischemia-reperfusion injury, remote ischemic preconditioning, pharmacological preconditioning.

\section{INTRODUCTION:}

Cardiopulmonary bypass (CPB) remains an essential element of the surgical correction of most major cardiovascular lesions. Despite significant advances in the technique, $\mathrm{CPB}$ is complicated by multisystem injury, the mechanisms of which include ischemia-reperfusion injury (IRI) and a detrimental systemic inflammatory response ${ }^{(\mathbf{1})}$. 
Remote ischemic preconditioning is a physiologic mechanism in mammalian species whereby brief exposure to nonlethal ischemia in one tissue confers protection against a prolonged ischemic insult in a distant tissue. Several clinical trials reported that remote ischemic preconditioning reduces myocardial injury after major cardiovascular surgery. Remote ischemic preconditioning is easily performed and likely to prove highly cost-effective. Large-scale trialsof the technique are warranted in patients undergoing major vascular surgery $^{(2)}$.

Preconditioning by sevoflurane is a pharmacological alternative to ischemic preconditioning(IPC). Patients who received sevoflurane for anesthesia during cardiac surgery had decreased postoperative mortality, less myocardial infarction and shorter length of hospital stay ${ }^{(3)}$.

Moreover, dexmedetomidine as a pharmacological preconditioning medication showed cardioprotective properties when administered prior to ischemia-reperfusion events (dexmedetomidine pre-conditioning). It acts as a selective $\alpha 2$-adrenoceptor agonist and offers good perioperative hemodynamic stability, reduced intraoperative anesthetic requirements and has proven antiinflammatory effects. Perio-perative dexmedetomidine use is associated with decreased postoperative mortality for up to 1 year, with decreased incidence of postoperative complications and delirium in patients undergoing cardiac surgery ${ }^{(4)}$.

\section{AIM OF THE WORK:}

The aim of this work was to compare remote ischemic preconditioning and pharmacological preconditioning in reducing cardiac injury induced by cardiopulmonary bypass in adult patients undergoing major aortic surgeries.

\section{PATIENTS AND METHODS:}

This randomized (sealed envelope) comparative prospective study has been carried out in Ain Shams University Hospitals between September 2017 and September 2019 after approval of Research Ethics Committee (REC) at Ain Shams University and written informed consent from all the patients.

Eligibility of patients for the study included age ranging from 40 to 70 years of both sexes who underwent major aortic surgery that needed cardiopulmonary bypass, and American Society of Anaesthesiologists (ASA) physical status of II-III.

\section{Exclusion criteria:}

Patients with the following criteria were excluded from the study: a previous unusual response to an anaesthetic, redo open heart surgeries, emergency surgeries, severe cardiac dysrhythmias, recent MI, valve insufficiency, ejection fraction below 30\%, advanced accompanying diseases such as hepatic, renal, airway and parenchymal lung diseases, cross-clamp time $\geq 120$ minutes and CPB time $\geq 90$ minutes, mortality at any step all over the study.

\section{Study procedure:}

Preoperatively, history and clinical examination were performed and evaluated for all patients. Also, routine investigations including complete blood count (CBC), random blood sugar (RBS), liver function test (LFT), kidney function test (KFT), prothrombin time (PT) and partial thromboplastin time (PTT) were done and evaluated for all patients.

At induction, an intravenous (IV) cannula was inserted, patient monitoring which consisted of five leads electrocardiogram (ECG), pulse oximetry, capnography, right internal jugular vein catheterization under adequate lidocaine 
subcutaneous anaesthesia, Invasive arterial blood pressure monitoring. Temperature was monitored via oesophageal probe after induction of anaesthesia.

Anaesthesia was uniformly induced by I.V. Midazolam $0.05 \mathrm{mg} / \mathrm{kg}$ and Fentanyl 5$10 \mu \mathrm{g} / \mathrm{kg}$. Endotracheal intubation was facilitated by cisatracurium at dose of 0.2 $\mathrm{mg} / \mathrm{kg}$ and maintained with total intravenous anaesthetics (TIVA) administration of propofol, fentanyl and cisatracurium. The lungs were mechanically ventilated with an inspired oxygen fraction $100 \%$, with tidal volume and respiratory rate adjusted to maintain end tidal carbon dioxide concentration of $32-35 \mathrm{mmHg}$.

Remote ischemic preconditioning was done after sternotomy by four cycles ( 5 mins of right lower limb ischemia and 5 mins reperfusion) using blood pressure cuff inflated to a pressure $15 \mathrm{mmHg}$ greater than systolic arterial blood pressure in the lower limb. Five to ten minutes were allowed to be the interval between completion of remote ischemic preconditioning cycles and initiation of bypass.

Pharmacological preconditioning was done after sternotomy by intermittent application of sevoflurane (two periods of sevoflurane application each lasting 5 minutes interspersed by 5 minutes washout on the basis of a previously published protocol for interrupted administration of sevoflurane for myocardial preconditioning) ${ }^{(5)}$. Sevoflurane was administered with high fresh gas flow $10 \mathrm{l} / \mathrm{min}$. After an end tidal concentration of 2 MAC was reached, fresh gas flow was reduced to 4 $1 /$ min. After 5 minutes sevoflurane was washed out by discontinuation of sevoflurane and increasing the fresh gas flow to $10 \mathrm{l} / \mathrm{min}$ to achieve a MAC value below 0.2. After 5 minutes this process was repeated for another time.Also, dexmedetomidine as a pharmacological preconditioning medication was administered as loading dose $1 \mu \mathrm{g} / \mathrm{kg}$ over 10 minutes and maintenance dose 0.2 to 0.7 $\mu \mathrm{g} / \mathrm{kg} / \mathrm{hr}$ five to ten minutes before initiation of bypass till the end of the operation.

All patients were operated upon through a standard midline sternotomy by the same team of surgeons. Anticoagulation was done through administration of heparin $(3 \mathrm{mg} / \mathrm{kg}$ I.V.), before aortic cannulation, to achieve Activated Coagulation Time (ACT) longer than $450 \mathrm{sec}$ or 3 times the control ACT. Immediately after placement of the aortic cross-clamp, diastolic arrest was achieved using antegrade, cold blood cardioplegia (ratio of blood to cardioplegia 4:1). Cardioplegia was given in a volume of 7 to $10 \mathrm{ml} / \mathrm{kg}$ for the initial arresting dose, with subsequent doses of 2.5 to $5 \mathrm{ml} / \mathrm{kg}$ given at 35-minute intervals throughout the crossclamp period. Surgery was conducted under conditions of tepid CPB (patient esophageal temperature of $32^{\circ} \mathrm{C}-35^{\circ} \mathrm{C}$ ) using a nonpulsatile flow rate of $2 \mathrm{~L} / \mathrm{min} / \mathrm{m}^{2}$ and a membrane oxygenator. Mean arterial blood pressure was maintained between 55 and 75 mm Hg during CPB.

At the conclusion of the surgical procedure, reperfusion of the heart was performed on an individual basis according to the protocol of weaning from CPB e.g., normal ABG, normal serum electrolytes, rewarming of the patient. 1 to $1.2 \mathrm{mg}$ of protamine sulphate was needed to reverse each $1 \mathrm{mg}$ of heparin after coming off bypass. The chest was then closed in routine fashion once meticulous haemostasis is achieved.

All patients were admitted to the intensive care unit for further management. Standard postoperative monitoring was performed through five leads electrocardiogram (ECG) with ST segment analysis, pulse oximetry, invasive blood pressure monitoring, central venous pressure (CVP) monitoring, urine output, core and skin temperature probes, with serial follow up of arterial blood gases (ABG). Decisions regarding inotropic support, airway and 
ventilator management were based on hemodynamic status, arterial blood pressure not responding to volume after a CVP of 15 $\mathrm{mmHg}$ and clinical judgment. Postoperative Inotropic therapy was standardized to treat a mean radial arterial blood pressure $<60 \mathrm{~mm}$ $\mathrm{Hg}$, despite optimization of preload, afterload, and heart rate. The patients were extubated when they were able to sustain adequate spontaneous respiration and required minimal oxygen support, as reflected by normal arterial blood gas levels. The patients were then discharged from ICU when they were hemodynamically stable with blood gas variables within normal range without the need of inotropic or oxygen support.

\section{Measurements:}

Cardiac enzymes indicating cardiac ischemia and injury induced by $\mathrm{CPB}$ were the primary outcome of the study. Measurements of CK total enzyme, CK MB enzyme, cardiac specific troponin I enzyme and inotropic support (adrenaline infusion) requirements were recorded before bypass and were repeated $3,6,12$, and 24 hours after bypass. Also, duration of postoperative intubation (hours) and postoperative ICU stay (days) were recorded.

\section{Statistical Analysis:}

Statistical Package for Social Sciences (SPSS) 20 was used for analyzing the results. Data were expressed as mean \pm SD and were compared using unpaired Student t-test. Chi square was used for comparing qualitative data. A value of $\mathrm{P} \leq 0.05$ was considered statistically significant.

\section{RESULTS}

Table 1: Demographic Data

\begin{tabular}{|l|c|c|c|}
\hline & Group R (n=21) & Group P (n=21) & P-value \\
\hline Sex (M/F) & $\begin{array}{c}12 / 9 \\
(57 \% / 43 \%)\end{array}$ & $\begin{array}{c}10 / 11 \\
(48 \% / 52 \%)\end{array}$ & 0.783 \\
\hline Age (years) & $55.14 \pm 9.46$ & $55.9 \pm 8.45$ & 0.987 \\
\hline ASA (II/III) & $11 / 10$ & $12 / 9$ & 0.808 \\
\hline $\begin{array}{l}\text { Thoracic aortic aneurysm } \\
\text { repair surgery }\end{array}$ & $9(43 \%)$ & $8(38 \%)$ & 0.841 \\
\hline Bentall procedure & $12(57 \%)$ & $13(62 \%)$ & II $=57 \%$ III $=43 \%$ \\
\hline
\end{tabular}

Data are presented as mean $\pm \mathrm{SD}$, ratio of patients $(\%)$. P-value $>0.05$ is considered statistically non-significant.

Table 1: shows that there was no statistically significant difference between the study groups regarding age, sex, ASA status and type of surgery.

Cardiac enzymes including CK total,
CK MB and cardiac specific troponin I were measured in the study groups at five-time intervals: after induction of general anaesthesia (before CPB), 3 hrs., 6 hrs., 12 hrs. and 24 hrs. after CPB respectively. 
Table 2: CK total enzyme (units/L)

\begin{tabular}{|c|c|c|c|}
\hline & Group $\mathrm{R}(\mathrm{n}=21)$ & Group P $(\mathrm{n}=21)$ & P-value \\
\hline After induction of GA & $71.761 \pm 10.922$ & $77.761 \pm 8.859$ & 0.057 \\
\hline $3 \mathrm{~h}$ & $83.523 \pm 8.459$ & $76.380 \pm 7.927$ & $0.007^{*}$ \\
\hline $6 \mathrm{~h}$ & $199.761 \pm 30.771$ & $183.714 \pm 16.520$ & $0.041^{*}$ \\
\hline $12 \mathrm{~h}$ & $180.761 \pm 13.692$ & $150.619 \pm 18.596$ & $<0.0001^{*}$ \\
\hline $24 \mathrm{~h}$ & $160.380 \pm 32.794$ & $153.571 \pm 22.885$ & 0.439 \\
\hline
\end{tabular}

Data are presented as mean $\pm \mathrm{SD} .{ }^{*} \mathrm{P}$-value $<0.05$ is considered statistically significant. GA (general anaesthesia).

As shown in table 2, levels of CK total enzyme revealed statistically significant

difference between both groups at 3 hours, 6 hours and 12 hours post CPB.

Table 3: CK MB enzyme (units/L)

\begin{tabular}{|c|c|c|c|}
\hline & Group R $(\mathrm{n}=21)$ & Group P $(\mathrm{n}=21)$ & P-value \\
\hline After induction of GA & $28.809 \pm 16.684$ & $22.809 \pm 11.813$ & 0.186 \\
\hline $3 \mathrm{~h}$ & $39.476 \pm 26.820$ & $35.952 \pm 25.987$ & 0.667 \\
\hline $6 \mathrm{~h}$ & $81.190 \pm 10.980$ & $63.190 \pm 24.689$ & $0.004^{*}$ \\
\hline $12 \mathrm{~h}$ & $57.571 \pm 25.519$ & $40.714 \pm 18.003$ & $0.017^{*}$ \\
\hline $24 \mathrm{~h}$ & $47 \pm 19.018$ & $37.904 \pm 20.486$ & 0.143 \\
\hline
\end{tabular}

Data are presented as mean \pm SD. ${ }^{*}$ P-value $<0.05$ is considered statistically significant. GA (general anesthesia).

Table 3 shows that levels of CK MB enzyme have statistically significant

difference between both groups at 6 hours and 12 hours post $\mathrm{CPB}$.

Table 4: Troponin I enzyme (ng/ml)

\begin{tabular}{|c|c|c|c|}
\hline & Group R $(\mathrm{n}=21)$ & Group P $(\mathrm{n}=21)$ & P-value \\
\hline After induction of GA & $0.018 \pm 0.016$ & $0.019 \pm 0.012$ & 0.819 \\
\hline $3 \mathrm{~h}$ & $5.265 \pm 1.682$ & $1.603 \pm 0.048$ & $<0.0001^{*}$ \\
\hline $6 \mathrm{~h}$ & $7.081 \pm 1.947$ & $3.737 \pm 0.596$ & $<0.0001^{*}$ \\
\hline $12 \mathrm{~h}$ & $13.07 \pm 3.806$ & $4.244 \pm 0.533$ & $<0.0001^{*}$ \\
\hline $24 \mathrm{~h}$ & $10.114 \pm 3.092$ & $2.436 \pm 0.049$ & $<0.0001^{*}$ \\
\hline
\end{tabular}

Data are presented as mean $\pm \mathrm{SD} .{ }^{*} \mathrm{P}$-value $<0.05$ is considered statistically significant. GA (general anesthesia).

Levels of cardiac specific troponin I enzyme at 3 hours, 6 hours, 12 hours and 24 hours post CPB were significantly higher in group $\mathrm{R}$ as compared with group $\mathrm{P}$ all over the study period, indicating lesser myocardial injury in group $\mathrm{P}$.

Table 5: Inotropic support (adrenaline infusion) requirements ( $\mathrm{ng} / \mathrm{kg} / \mathrm{min}$ )

\begin{tabular}{|c|c|c|c|}
\hline & Group R $(\mathrm{n}=21)$ & Group P $(\mathrm{n}=21)$ & P-value \\
\hline After induction of GA & 0 & 0 & inv \\
\hline $3 \mathrm{~h}$ & $89.714 \pm 1.383$ & $74.428 \pm 1.287$ & $<0.0001^{*}$ \\
\hline $6 \mathrm{~h}$ & $109.333 \pm 2.287$ & $74.952 \pm 1.465$ & $<0.0001^{*}$ \\
\hline $12 \mathrm{~h}$ & $71.619 \pm 2.801$ & $64.38 \pm 1.909$ & $<0.0001^{*}$ \\
\hline $24 \mathrm{~h}$ & $67.857 \pm 1.236$ & $59.476 \pm 1.249$ & $<0.0001^{*}$ \\
\hline
\end{tabular}

Data are presented as mean \pm SD. ${ }^{*}$ P-value $<0.05$ is considered statistically significant. GA (general anesthesia). 
Regarding inotropic support (adrenaline infusion) requirements in both groups, they were significantly higher in group $\mathrm{R}$ as compared with group $\mathrm{P}$ all over the study.

Table 6: Length of postoperative intubation (hours) and postoperative ICU stay (days)

\begin{tabular}{|l|c|c|c|}
\hline & Group R (n=21) & Group P (n=21) & P-value \\
\hline $\begin{array}{l}\text { Length of postoperative } \\
\text { intubation (hours) }\end{array}$ & $60.38 \pm 15.011$ & $29.19 \pm 9.217$ & $<0.0001^{*}$ \\
\hline $\begin{array}{l}\text { Length of postoperative ICU stay } \\
\text { (days) }\end{array}$ & $7.285 \pm 2.239$ & $2.904 \pm 1.894$ & $<0.0001^{*}$ \\
\hline
\end{tabular}

Data are presented as mean $\pm \mathrm{SD} .{ }^{*} \mathrm{P}$-value $<0.05$ is considered statistically significant.

Regarding length of postoperative intubation and postoperative ICU stay, there was highly statistically significant difference between both groups as revealed in table 6 .

\section{DISCUSSION:}

The current study showed that for patients undergoing major aortic surgeries, there was statistically significant differences between both groups regarding cardiac enzymes (CK total, CK-MB and trop I), inotropic support, length of postoperative intubation and postoperative ICU stay which were much higher in group $\mathrm{R}$ than group $\mathrm{P}$.

Regarding CK total enzyme, the current study revealed that there was statistically significant elevation in levels of $\mathrm{CK}$ total enzyme in group $\mathrm{R}$ at 3, 6 and 12 hours post $\mathrm{CPB}$ in comparison to group $\mathrm{P}$. Also, as regards CK-MB enzyme, there was statistically significant difference between both groups at 6 and 12 hours post $\mathrm{CPB}$ which was higher in group $\mathrm{R}$ than group $\mathrm{P}$.

To our knowledge, there is no studies which assessed or compared RIPC versus pharmacological preconditioning via sevoflurane and dexmedetomidine in adult patients undergoing major aortic surgeries. Also, there is a wide range of surgical procedures with different techniques of preconditioning.

As regards RIPC, a study which was conducted by Iliodromitis and his colleagues in (2006) showed that there was no statistically significant difference regarding CK total enzyme levels in RIPC group as compared with control group (no intervention) in patients undergoing percutaneous coronary intervention $(\mathrm{PCI})^{(\mathbf{6})}$.

Another study conducted by Gunaydin et al. in (2000) comparing RIPC group with control group (no intervention) and showed that levels of $\mathrm{CK}$ total enzyme tended to increase throughout the study but without significant difference between both groups in patients undergoing coronary artery surgery. Also, they showed that levels of CK-MB enzyme had no significant difference between both groups ${ }^{(7)}$.

Also, Lomivorotov and his colleagues in (2012) conducted a study on patients undergoing $\mathrm{CABG}$ surgery and divided them into two groups; RIPC group and control group (deflated cuff placed on the right upper arm for 30 minutes). They found that there was no statistically significant difference in CK-MB enzyme levels between both groups before $\mathrm{CPB}$ and at 6 and 24 hours post $\mathrm{CPB}{ }^{(8)}$.

Another study which was conducted by Karuppasamy et al. in (2011) on patients undergoing CABG surgery dividing them into RIPC group and control group (placebo without cuff inflation). They revealed that there was no statistically significant difference between both groups regarding CK-MB levels before CPB and at 6,12 and 24 hours post $\mathrm{CPB}^{(\mathbf{9})}$.

On the contrary, Ali and his colleagues in (2010) conducted a study on patients undergoing $\mathrm{CABG}$ surgery dividing them into RIPC group and control group (were not subjected to limb ischemia). They found that 
levels of CK-MB enzyme were significantly lower in RIPC group in comparison with control group at 8, 16 and 24 hours after surgery ${ }^{(10)}$.

Regarding sevoflurane preconditioning, in the work of Soliman and Abukhudair in (2017) comparing sevoflurane and isoflurane administration in patients undergoing $\mathrm{CABG}$ surgery, they found that CK-MB enzyme levels were not significantly different between both groups before CPB. However, their levels increased in both groups after CPB with marked elevation in isoflurane group through the first 24 hours postoperative $^{(\mathbf{1 1})}$.

Also, in the work of Bein and his colleagues in (2008), they revealed that interrupted administration of sevoflurane had lower levels of CK-MB enzyme at 24 hours postoperatively than both propofol only group and continuous sevoflurane administration group in patients undergoing CABG surgery ${ }^{(12)}$.

On the other hand, in the work of Julier and his colleagues in (2003), they conducted a study on patients scheduled for CABG surgery and they were randomly assigned to preconditioning with either placebo (oxygen-air mixture only) or 2 MAC of sevoflurane as an inhalational anesthetic. They revealed that a significant postoperative increase in CK total enzyme levels was observed in both groups; however, there was no statistically significant difference between them. Also, they found that there was no statistically significant difference regarding CK-MB enzyme levels between sevoflurane and placebo group ${ }^{(13)}$.

Frassdorf and his colleagues in (2009) compared CK total enzyme levels between 3 groups; sevoflurane I group (1 MAC for 5 minutes), sevoflurane II group (2 times of 1 MAC for 5 minutes interspersed by 5 minutes washout) and control group (total intravenous anesthesia with sufentanil and propofol only) in patients undergoing $\mathrm{CABG}$ surgery and they found that there was no statistically significant difference between the three groups. Also, they found that there was no statistically significant difference between sevoflurane groups and control group regarding CK-MB enzyme levels ${ }^{(5)}$.

The difference between the results of the previous two studies and the current study may be due to the different type of surgery and the use of a single agent as pharmacological preconditioning.

As regards dexmedetomidine preconditioning, Ren et al. in (2013) revealed that dexmedetomidine administration in patients undergoing off pump CABG surgery can reduce CK-MB enzyme levels significantly as compared to control group (administration of physiological saline) immediately after surgery and at 12 hours postoperatively ${ }^{(14)}$.

Regarding troponin I enzyme, its levels at 3 hours, 6 hours, 12 hours and 24 hours post CPB were significantly higher in group $\mathrm{R}$ as compared with group $\mathrm{P}$ all over the study period, indicating lesser myocardial injury in group P. Also, the current study revealed that group $\mathrm{R}$ had higher levels of inotropic support (adrenaline infusion) requirements than group $\mathrm{P}$ all over the study.

As regards RIPC, in the work of Lomivorotov and his colleagues in (2012) comparing RIPC against control group showed that troponin I enzyme concentrations peaked at 6 hours post CPB in both groups without significant difference at any time point between both groups ${ }^{(8)}$.

Another study conducted by Karuppasamy et al. in (2011) revealed that there was no statistically significant difference in troponin I enzyme concentration between RIPC and control groups. They also found that inotropic support requirements were the same in RIPC and control groups ${ }^{(9)}$. 


\section{Gihan S. El Nasr, et al.,}

Furthermore, Rahman and his colleagues in (2010) revealed that RIPC in patients undergoing CABG surgery did not reduce inotropic support and vasoconstrictor requirements as compared with control group $^{(15)}$.

Regarding pharmacological preconditio-ng with sevoflurane and dexmedetomidine in the work of Zhou et al. in (2019), they found that combined administration of dexmedetomidine with sevoflurane remarkably lowered troponin I enzyme levels at 6,12 , and 24 hours postoperatively as compared to sevoflurane only group in patients undergoing cardiac valve replacement surgeries ${ }^{(16)}$.

As regards sevoflurane preconditioning in the work of Frassdorf et al. in (2009), they revealed that administration of sevoflurane for 5 minutes twice interrupted by 5 minutes washout can reduce significantly myocardial injury measured by troponin I enzyme (peak level $7 \pm 2 \mathrm{ng} / \mathrm{ml}$ ) as compared with controls ${ }^{(5)}$.

Also, Soliman and Abukhudair in (2017) found that there was significant difference in troponin I enzyme concentrations between sevoflurane and isoflurane groups postoperatively, which were higher in isoflurane group. They also revealed that preconditioning using sevoflurane can reduce inotropic support requirements as compared with isoflurane preconditioning ${ }^{(11)}$.

On the contrary to the previous studies, Piriou and his colleagues in (2007) found that there was no statistically significant difference as regards troponin I enzyme concentrations between sevoflurane preconditioning and control groups (no intervention) throughout the study in patients undergoing CABG surgery. Moreover, they revealed that inotropic support requirements did not differ significantly in sevoflurane group in comparison to control groups ${ }^{(17)}$.
Also, Soro and his colleagues in (2012) revealed that there was no statistically significant difference between propofol and sevoflurane groups regarding concentrations of troponin I enzyme in patients undergoing CABG surgery. Furthermore, they showed that there was no statistically significant difference regarding inotropic support requirements between sevoflurane and propofol groups $^{(18)}$.

The difference between the results of the previous two studies and the current study could be due to the different type of surgery, the use of a different technique for sevoflurane preconditioning (1 MAC of sevoflurane for 15 minutes followed by 15 mins washout in Piriou et al., 2007 ${ }^{(17)}$ and continuous sevoflurane inhalation in Soro et al., $2012^{(18)}$ and the use of a single agent as pharmacological preconditioning.

For dexmedetomidine preconditioning, Ren and his colleagues in (2013) found that administration of dexmedetomidine could decrease troponin I enzyme levels significantly as compared with control group immediately postoperatively and at 12 hours postoperatively. Moreover, they found that dexmedetomidine administration can reduce inotropic support requirements significantly in comparison to control group ${ }^{(14)}$.

Another study conducted by Soliman and Zohry in (2016) showed that dexmedetomidine administration in high risk patients undergoing aortic vascular surgery could reduce troponin I enzyme levels at 12 and 24 hours postoperatively in comparison with control group (equal volume of normal saline). Furthermore, they showed that inotropic support was required in control group more than dexmedetomidine group ${ }^{(19)}$.

The present study showed that group $\mathrm{R}$ had statistically significant longer duration of both postoperative intubation and postoperative ICU stay than group P.

As regards RIPC, Lomivorotov et al. in (2012) found that there was no statistically 
significant difference between RIPC and control groups as regards duration of both postoperative intubation and postoperative ICU stay ${ }^{(8)}$.

Also, Karuppasamy and his colleagues in (2011) revealed that duration of both postoperative intubation and postoperative ICU stay were not statistically significant different between RIPC and control groups $^{(9)}$.

Regarding sevoflurane preconditioning, Soliman and Abukhudair in (2017) revealed that sevoflurane preconditioning could shorten the duration of postoperative ICU stay in comparison with isoflurane group ${ }^{(11)}$.

On the contrary to the previous study, Soro and his colleagues in (2012) revealed that sevoflurane preconditioning did not differ in duration of postoperative ICU stay in comparison with propofol preconditioning (17)

The results of the previous study were different from the current study due to the different type of surgery, the use of a different technique for sevoflurane preconditioning (continuous sevoflurane inhalation) and the use of a single agent as a pharmacological preconditioning.

For dexmedetomidine preconditioning, Ren et al. in (2013) showed that dexmedetomidine administration could shorten the duration of both postoperative intubation and postoperative ICU stay as compared with control group ${ }^{(14)}$.

Conclusion:

The results demonstrate that pharmacological preconditioning using sevoflurane and dexmedetomidine has myocardial protective effect after $\mathrm{CPB}$ in adult patients undergoing major aortic surgeries more than remote ischemic preconditioning as reflected by lower elevation in $\mathrm{CK}$ total enzyme, $\mathrm{CK} \mathrm{MB}$ enzyme and troponin I enzyme and decreased inotropic support (adrenaline) requirements postoperatively along with shorter duration of both postoperative intubation and postoperative ICU stay. Based on this study, pharmacological preconditioning using sevoflurane and dexmedetomidine is recommended for myocardial protection after $\mathrm{CPB}$ in adult patients undergoing major aortic surgeries.

\section{Recommendations:}

We recommend performing this study on ischemic cardiac patients scheduled for coronary artery bypass grafting (CABG) to precisely assess the effect of preconditioning on ischemic myocardium in both groups, taking in consideration the limitations of the current study.

\section{REFERENCES:}

1. Kunst $G$ and Klein AA: Peri-operative anaesthetic myocardial preconditioning and protection - cellularmechanisms and clinical relevance in cardiac anaesthesia: review article.Anaesthesia 2015; 70:467482.

2. Stewart RW, Tjun YT, Umar S, et al.: Remote ischemic preconditioning in major vascular surgery. J Vasc Surg 2009; 49:240-3

3. Axel F,Kunath $S$, Dana V, et al.: Effect of ischemic and pharmacological preconditioning of lower limb muscle tissue on tissue oxygenation measured by nearinfrared spectroscopy: pilot study. BMC Anesthesiol. 2014; 14:54.

4. Ji F, Li Z, Nguyen H, et al.: Perioperative dexmedetomidine improves outcomes of cardiac surgery. Circulation. 2013; 127:1576-1584.

5. Frassdorf J, Borowski A, Ebel D, et al.: Impact of preconditioning protocol on anesthetic-induced cardioprotection in patients having coronary artery bypass surgery. The Journal of Thoracic and Cardiovascular Surgery. 2009; 137(6), 1436-1442.e2.

6. Iliodromitis EK, Kyrzopoulos $S$, Paraskevaidis IA, et al.: Increased $C$ 


\section{Gihan S. El Nasr, et al.,}

reactive protein and cardiac enzyme levels after coronary stent implantation. Is there protection by remote ischaemic preconditioning? Heart. 2006; 92(12), 1821-1826.

7. Günaydin B, Çakici I, Soncul H, et al.: Does remote organ ischaemia trigger cardiac preconditioning during coronary artery surgery? Pharmacological Research. 2000; 41(4), 493-496.

8. Lomivorotov $V V$, Shmyrev $V A$, Nepomnyaschih VA, et al.: Remote ischaemic preconditioning does not protect the heart in patients undergoing coronary artery bypass grafting. Interactive CardioVascular and Thoracic Surgery. 2012; 15(1), 18-22.

9. Karuppasamy $P$, Chaubey $S$, Dew $T$, et al.: Remote intermittent ischemia before coronary artery bypass graft surgery: a strategy to reduce injury and inflammation? Basic Research in Cardiology. 2011; 106(4), 511-519.

10. Ali $N$, Rizwi $F$, Iqbal A, et al.: Induced remote ischemic pre-conditioning on ischemia-reperfusion injury in patients undergoing coronary artery bypass. J Coll Physicians Surg Pak. 2010; 20(7):427-431.

11. Soliman $R$ and Abukhudair $W$ : Comparison of the myocardial protective effect of sevoflurane and isoflurane in high-risk cardiac patients undergoing coronary artery bypass grafting surgery: a randomized study. The Egyptian Journal of Cardiothoracic Anesthesia. 2017; 11(3), 38.

12. Bein B, Renner J, Caliebe D, et al.: The effects of interrupted or continuous administration of sevoflurane on preconditioning before cardio-pulmonary bypass in coronary artery surgery: comparison with continuous propofol. Anaesthesia. 2008; 63(10), 1046-1055.
13. Julier $K$, da Silva $R$, Garcia $C$, et al.: Preconditioning by Sevoflurane Decreases Biochemical Markers for Myocardial and Renal Dysfunction in Coronary Artery Bypass Graft Surgery: A Double-blinded, Placebo-controlled, Multicenter Study. Anesthesiology. 2003; 98(6), 1315-1327.

14. Ren J, Zhang H, Huang L, et al.: Protective effect of dexmedetomidine in coronary artery bypass grafting surgery. Experimental and Therapeutic Medicine. 2013; 6(2), 497-502.

15. Rahman IA, Mascaro JG, Steeds RP, et al.: Remote ischemic preconditioning in human coronary artery bypass surgery from promise to disappointment? Circulation. 2010; 122: S53-S59.

16. Zhou HM, Ling XY, Ni YJ, et al.: Precardiopulmonary bypass administration of dexmedetomidine decreases cardiac troponin I level following cardiac surgery with sevoflurane postconditioning. J Int Med Res. 2019; 47(8):3623 3635.

17. Piriou V, Mantz J, Goldfarb $G$, et al.: Sevoflurane preconditioning at 1 MAC only provides limited protection in patients undergoing coronary artery bypass surgery: a randomized bi-centre trial. British Journal of Anesthesia. 2007; 99(5), 624-631.

18. Soro $M$, Gallego L, Silva $V$, et al.: Cardioprotective effect of sevoflurane and propofol during anesthesia and the postoperative period in coronary bypass graft surgery. European Journal of Anesthesiology. 2012; 29(12), 561-569.

19. Soliman $R$ and Zohry $G$ : The myocardial protective effect of dexmedetomidine in high-risk patients undergoing aortic vascular surgery. Annals of Cardiac Anaesthesia. 2016; 19(4), 606. 


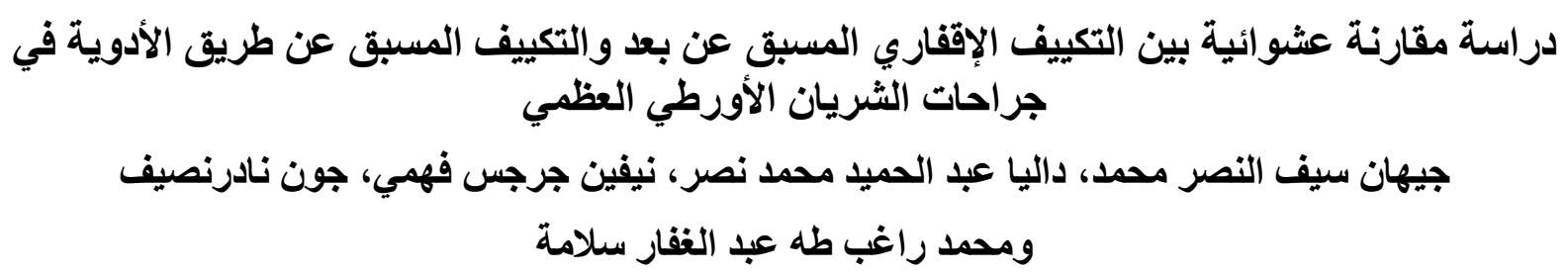

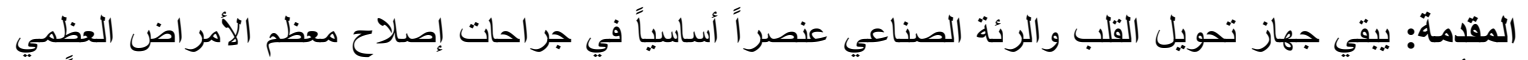

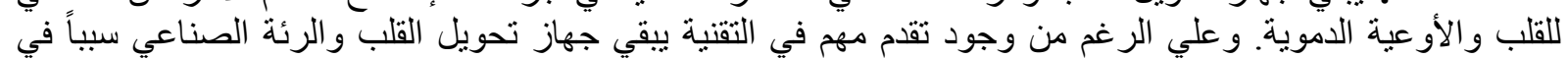

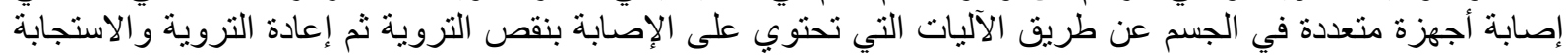

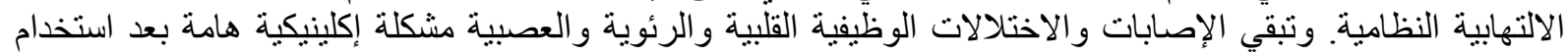
جهاز تحويل القلب و الرئة الصناعية الإصنابي.

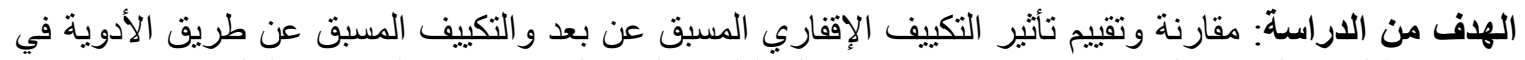

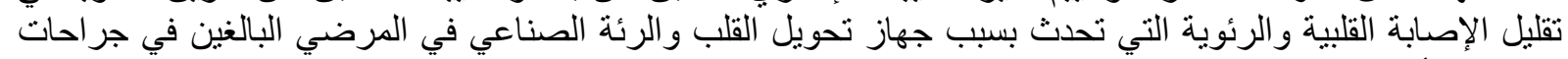
الشريان الأورطي العظي.

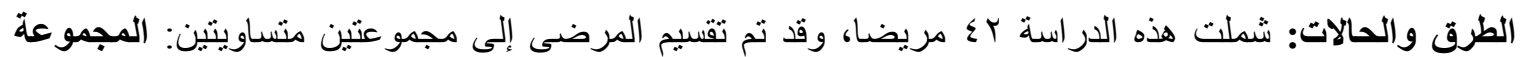

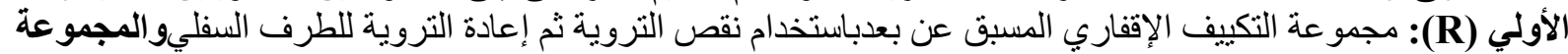
الثانيةة (P): مجمو عة التكييف المسبق عن طريق الأدوية باستخدام عقاري السيفو فلورين و الديكسميدينو ميدين.

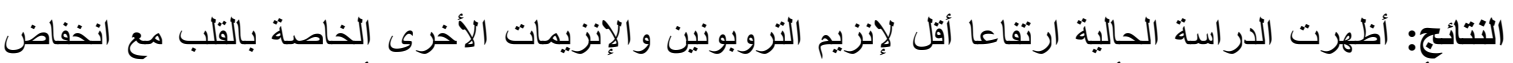

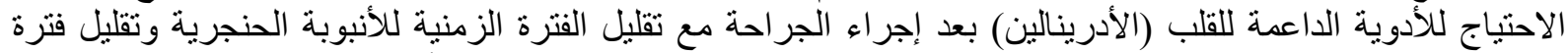

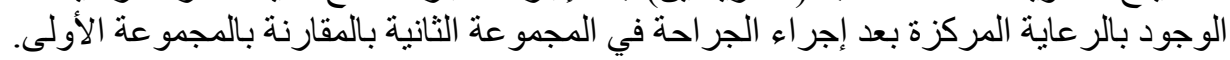

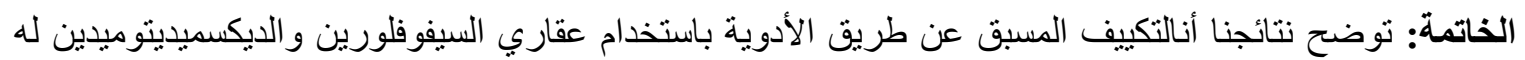

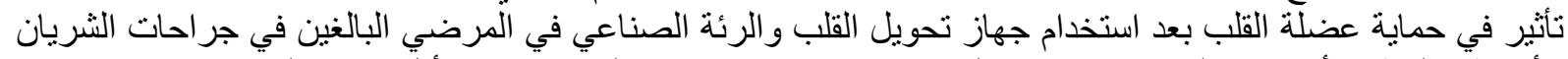

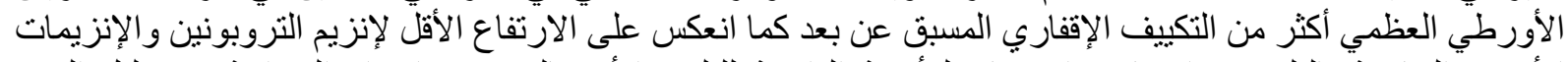

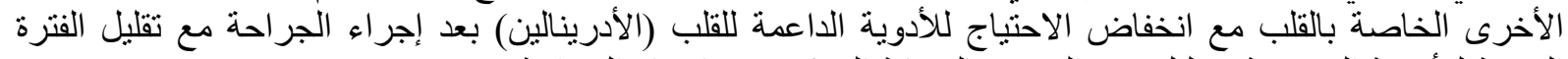

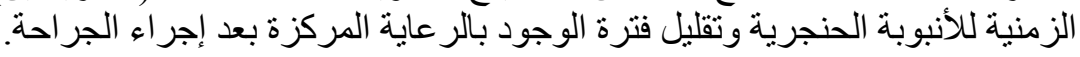

